\title{
Estigma e violência na percepção dos profissionais de saúde mental de uma unidade psiquiátrica em hospital geral
}

\author{
Stigma and violence in the perception of mental health \\ professionals of a psychiatric unit in a general hospital
}

\author{
Raquel Silva Barretto ${ }^{1}$ (D), Ana Elisa Bastos Figueiredo ${ }^{1}$
}

\begin{abstract}
Resumo
Introdução: O artigo em questão é fruto de uma pesquisa no âmbito da saúde mental, em um dos dispositivos potencializados após a década de 1990. Objetivo: A investigação teve como objetivo geral compreender a percepção dos profissionais de saúde mental, atuantes em uma Unidade Psiquiátrica de Hospital Geral, sobre os termos estigma e violência. Método: Trata-se de pesquisa exploratória, descritivo-analítica com abordagem qualitativa. Teve como campo a Unidade de Internação Psiquiátrica de um Hospital Geral Universitário, no município do Rio de Janeiro. Os sujeitos da pesquisa foram 06 profissionais de saúde mental. Após a liberação dos Comitês de Ética, autorização da direção e o preenchimento dos Termos de Consentimento, o passo posterior envolveu as entrevistas semiestruturadas. Optou-se pela análise de conteúdo para trabalhar os dados obtidos. Resultados: Enquanto alguns profissionais demonstraram desconhecer o significado de estigma, o termo violência foi exemplificado através de conceituações e aproximações com a realidade social. As diversas falas sobre a violência simbólica ganharam destaque. Ao mencioná-la, reconheceram que determinadas práticas junto aos pacientes, ainda que não agreguem violências de ordem física, reproduzem a estigmatização, que repercute na violência psicológica e nas negligências. Conclusão: Ainda que a mudança no cuidado tenha se estabelecido, faz-se necessário o conhecimento do processo da violência e estigmatização nas práticas atuais, dado que tais fenômenos podem agravar o sofrimento existente.
\end{abstract}

Palavras-chave: psiquiatria; saúde mental; violência; estigma; internação psiquiátrica.

\begin{abstract}
Background: This research emphasized violence in the mental health area, one of the devices strengthened after the 1990 s. Objective: The general objective of the research was to understand the perception of mental health professionals working in a General Hospital Psychiatric Unit on stigma and violence. Method: This is exploratory, descriptive-analytical research with a qualitative approach. It was carried out in the Psychiatric Hospitalization Unit of a General University Hospital in the city of Rio de Janeiro. The participants of the research were 06 mental health professionals. After the release of the Ethics Committees, management authorization and the completion of the Terms of Consent, semi-structured interviews were performed. The content analysis was opted to work the obtained data. Results: While some professionals demonstrated to be unaware of the meaning of stigma, the term violence was exemplified through conceptualizations and approximations with social reality. The various speeches on symbolic violence gained prominence. When mentioning it, they recognized that certain practices with patients, even if they do not add physical violence, reproduce stigmatization, which has repercussions on psychological violence and negligence. Conclusion: Although the change in care has been established, it is necessary to know the process of violence and stigmatization in current practices, since such phenomena can aggravate the existing suffering.
\end{abstract}

Keywords: psychiatry; mental health; violence; stigma; psychiatric hospitalization.

${ }^{1}$ Programa de Pós-graduação em Saúde Pública, Escola Nacional de Saúde Pública Sérgio Arôuca (ENSP), Fundação Oswaldo Cruz (FIOCRUZ) - Rio de Janeiro (RJ), Brasil.

Trabalho realizado no Programa de Pós-graduação em Saúde Pública, Escola Nacional de Saúde Pública Sérgio Arôuca (ENSP), Fundação Oswaldo Cruz (FIOCRUZ) - Rio de Janeiro (RJ), Brasil.

Endereço para correspondência: Raquel Silva Barretto - Programa de Pós-graduação em Saúde Pública, Escola Nacional de Saúde Pública Sérgio Arôuca (ENSP), Fundação Oswaldo Cruz (Fiocruz), R. Leopoldo Bulhões, 1480 - Manguinhos - CEP: 21041-210 - Rio de Janeiro (RJ), Brasil - Email: psi_quel@yahoo.com.br

Fonte de financiamento: nenhuma.

Conflito de interesses: nada a declarar.

Este é um artigo publicado em acesso aberto (Open Access) sob a licença Creative Commons Attribution, que permite uso, distribuição e reprodução em qualquer meio, sem restrições desde que o trabalho original seja corretamente citado. 


\section{INTRODUÇÃO}

Violência é um fenômeno antigo na história humana. O termo sugere diversas associações principalmente com a agressividade e a coerção física ${ }^{1}$. No imaginário social, pode-se perceber que ainda está intimamente atrelada aos contornos físicos.

De grande importância nesse contexto, a Organização Mundial da Saúde, no Relatório Mundial Sobre Violência e Saúde, define violência como "o uso intencional da força física ou do poder, real ou em ameaça, dirigido a outrem, de forma que resulte ou tenha a possibilidade de resultar em danos físicos ou psicológicos"2.

O Ministério da Saúde assumiu oficialmente a temática, em 2001, com a publicação da Política Nacional de Redução da Morbimortalidade por Acidentes e Violências ${ }^{3}$.

O cenário nacional é marcado por alto índice de violências e acidentes, que aumentam relativamente os gastos dos serviços de saúde com internações, tratamentos, medicalizações e capacitação de profissionais. Esses eventos trazem como consequência também sequelas permanentes e a redução da expectativa de vida, principalmente da população jovem, a mais afetada pelos acidentes e violências ${ }^{1,3}$.

No entanto, a violência de natureza psicológica, que gera importantes impactos na saúde, tem sido menos documentada nas pesquisas. Pouco se fala das violências e dos abusos psicológicos, que trazem consequências diversas para a saúde e atingem de formas diferenciadas os grupos destacados como mais vulneráveis, entre eles os indivíduos com transtornos mentais, os idosos, as crianças e as mulheres.

No caso dos sujeitos com transtornos mentais, o avanço da Reforma Psiquiátrica Brasileira possibilitou o surgimento de novos dispositivos de atenção à saúde mental, os quais visaram, dentre outros objetivos, reduzir a violência institucional.

O Ministério da Saúde (MS), diante das mudanças no modelo assistencial, propôs a substituição progressiva dos leitos psiquiátricos para os leitos de atenção integral em saúde mental ${ }^{4}$.

As Unidades Psiquiátricas dos Hospitais Gerais estão inclusas nos Leitos de Atenção Integral e são a porta de entrada da rede assistencial, que visam ofertar o acolhimento integral do paciente em crise, estando articulados com outros dispositivos de referência para o paciente ${ }^{5}$. Os novos dispositivos estão diretamente relacionados à desospitalização e desinstitucionalização.

A desospitalização situa um conjunto de práticas para além do desmonte hospitalar ${ }^{6}$. Contemporaneamente, no âmbito do SUS, o Programa de Desinstitucionalização propõe, através do trabalho realizado pelas equipes de saúde, reabilitar psicossocialmente, reorganizar os espaços de internação e as ações, rearticular vínculos familiares e garantir a promoção à saúde ${ }^{7}$.

$\mathrm{O}$ interesse pelo estigma, por sua vez, foi ao encontro de autores como Goffman ${ }^{8}$, Becker ${ }^{9}$ e Minayo ${ }^{1}$, ao afirmarem que o estigma e a violência, de modo geral, são capazes de afetar a saúde dos indivíduos, produzindo ou agravando patologias e transtornos já existentes, e a imersão nessa temática aparece como interesse para a saúde mental, perpassada pelo campo da saúde coletiva.

Embora outros autores estejam surgindo no âmbito do estigma, os dois primeiros são clássicos nos estudos sobre o tema. O primeiro menciona o estigma como uma conotação muito antiga e seu cerne subjaz ao meio cultural e social. A sociedade busca subterfúgios para estabelecer atributos e categorias que se incluem no perfil de um "ser normal e normativo". Desse modo, aqueles que não se enquadram ao que a sociedade define como normal e normativo são passíveis de sofrer atos estigmatizantes. A estranheza entre a identidade social e o padrão social compõe o que Goffman pontua como discrepância entre a identidade social virtual e a identidade social real. Sendo assim, o indivíduo é depreciado naquele grupo que já passou por um processo de ressignificação e categorização diferenciando-se previsível normativamente em um estereótipo.

O autor considera a existência de 03 tipos de estigma: o de ordem física corporal, como deformações; as culpas de caráter individual ou não naturais, marcadas por vontades fracas, crenças falsas; e paixões tirânicas, entrando nesse âmbito as pessoas com transtornos mentais, alcoolistas, homossexuais, e os estigmas tribais das raças, nações e religiões ${ }^{8}$.

Goffman observa que, por pertencer a um meio social, o estigmatizado também tem as crenças e aspirações do devir identitário compartilhado por todos e se reconhece com alguém que engloba a realidade "normal", como os outros, mas as expectativas sociais e excludentes vão aos poucos agindo sobre esses sujeitos, que em algum momento percebem-se como diferentes em algum de seus atributos e incorporam sentimentos de depreciação, vergonha e inferioridade. Afirma-se então a vitimização do sujeito estigmatizado ${ }^{8}$.

O segundo autor, em investigações mais recentes, reafirmou a estigmatização em relação aos que infringem regras do "certo" ou "errado" e não conseguem estabelecer uma rotina próxima às determinadas por um grupo ${ }^{9}$. Na perspectiva do desvio, busca entender por que algumas pessoas não conseguem cumprir as regras, e para isso utiliza a relação médico-paciente, principalmente do ponto de vista das nosologias psiquiátricas, em que qualquer mau funcionamento do indivíduo, não importava em relação a que regra, era considerado um sinal de doença mental. O autor traz uma novidade em relação ao desvio como a "não obediência" às regras sociais, quando diz que os indivíduos estão inseridos em diversos grupos sociais, e nem sempre quando não seguem a norma de um deles significa que estão descumprindo as normas de outros grupos.

Aproxima-se dos atributos de estigma mencionados por Goffman, quando afirma que tendemos a buscar características próprias para os desviantes, ou padrões sociais que os diferenciem, 
mas ao mesmo tempo os categorizem e os tornem homogêneos. Para um ato ser ou não desviante depende de como outras pessoas reagem a ele $^{9}$.

Becker ainda ressalta que nem sempre o "desvio" em um período histórico será considerado o mesmo desvio em outro.

Ao longo do processo da Reforma Psiquiátrica, os estudos sobre violência e estigma destacaram as mudanças que as instituições psiquiátricas sofreram.

Basaglia, importante precursor da Reforma Psiquiátrica, mencionou que a doença se transforma à medida que a instituição psiquiátrica sofre transformações ${ }^{10}$.

A presente investigação teve como objetivo principal conhecer o que os profissionais de saúde mental, atuantes em uma unidade psiquiátrica de hospital geral, compreendiam por "estigma” e "violência". Os demais objetivos visaram analisar se, na opinião desses profissionais, o estigma e a violência eram de alguma forma reproduzidos nesse espaço em questão e, por fim, se na visão dos entrevistados o estigma como expressão da violência poderia agravar os sofrimentos já existentes.

\section{MÉTODO}

Foi realizada uma pesquisa exploratória, descritivo-analítica com abordagem qualitativa.

A investigação ocorreu no município do Rio de Janeiro, em um Hospital Universitário, que dispõe de Unidade Psiquiátrica para internação. Tal hospital se destaca por ser o segundo maior em número de leitos psiquiátricos no município, se comparado a outros hospitais públicos. Sua gestão é pública, na esfera federal.

A unidade psiquiátrica é diretamente administrada pelo hospital. Essa Unidade Psiquiátrica de Hospital Geral funciona integralmente, 24 horas por dia, durante os 7 dias da semana. Possui 12 leitos de internação psiquiátrica. A equipe oficial da psiquiatria é composta por 21 membros, subdividida em psiquiatras, psicólogos e técnicos administrativos, funcionando com número reduzido de profissionais, pois ainda está em fase de implementação. Além dos profissionais citados, possui 3 enfermeiros e 3 técnicos de enfermagem, entretanto, estes não são contabilizados dentro da equipe oficial, uma vez que são cedidos do hospital para o serviço.

A coleta de dados se deu por meio de entrevistas semiestruturadas, seguindo um roteiro previamente estabelecido, elaborado pelas pesquisadoras, que contemplaram o conhecimento dos conceitos "violência", "estigma" e a aplicação prática destes.

Foram entrevistados seis (06) profissionais de saúde mental nas categorias: enfermagem três (03) e psiquiatria três (03); quatro (04) do sexo masculino e dois (02) do sexo feminino; as idades variaram entre 27 e 65 anos, sendo que cinco (05) participantes tinham mais de 40 anos. Os critérios de inclusão foram definidos da seguinte forma: profissionais de nível superior, com vínculo empregatício com a Instituição, alocados há pelo menos 06 meses na Unidade Psiquiátrica do Hospital Geral, pertencentes às categorias que estavam presentes nos serviços nos dias em que a pesquisadora compareceu à Unidade.

A presente Unidade Psiquiátrica possui como membros fixos os profissionais de nível superior, por isso a escolha destes. O período de 06 meses foi escolhido como ponto de corte porque é um tempo suficiente para a adaptação e conhecimento dos profissionais sobre a estrutura e a rotina daquela unidade. Os critérios de exclusão foram: alunos da residência médica, profissionais recém-admitidos ou sem vínculo empregatício com a Instituição, pertencentes às categorias que não estavam presentes nas idas da pesquisadora ao campo. Embora os psicólogos façam parte da equipe, elesnão foram incluídos, ou por não estarem presentes nas idas da pesquisadora, ou por se encontrarem indisponíveis para responder à pesquisa.

A pesquisa ocorreu em conformidade com a Resolução 466 do CNS, que estabelece questões éticas e legais. O Comitê de Ética principal foi o da Escola Nacional de Saúde Pública (ENSP/Fiocruz), e o número do processo aprovado em 17/06/2015 foi: 1.108.410. O parecer do Hospital como coparticipante da pesquisa, liberado em $02 / 07 / 2015$, foi 1.143 .128 . Todos os sujeitos da pesquisa concordaram com ela e assinaram o TCLE.

A forma de análise de dados foi a análise temática (AT), descrita por Braun e Clarcke em 2006 e aplicada inicialmente em estudos psicológicos ${ }^{11}$. É um método analítico utilizado nas investigações de cunho qualitativo, que busca analisar fenômenos com base nos dados trabalhados. Na AT, identificam-se, analisam-se e relatam-se padrões (temas), além de interpretar aspectos do tema escolhido ${ }^{11}$. O que, por sua vez, é definido como a essência da questão, algo que prevalece nos dados ou que merece atenção, não devendo ser confundido com a medida de prevalência, visto que não é quantitativo. $\mathrm{O}$ tema pode ser um aspecto particular encontrado nos dados.

Um dos benefícios da AT é a sua flexibilidade, uma vez que não é limitada a nenhuma posição epistemológica ou teórica, admitindo então a aplicação dentro de diversas abordagens. A liberdade teórica permite um relato mais amplo, rico e detalhado. Porém, o (a) pesquisador (a) pode realizar uma análise inconsistente, baseada na ideia de que "tudo é admitido" quando não tem clareza e conhecimento para fazê-la. Outro benefício consiste no fato de a análise ser acessível, não requerendo nenhum programa ou tecnologia complexa para a sua realização.

Seguindo os passos orientados por Braun e Clarcke ${ }^{11}$, o material foi transcrito e lido, os subtemas foram sistematizados, as entrevistas relidas, os estratos foram agrupados dentro de perguntas, contendo temas principais.

As questões seguiram uma lógica segundo a qual primeiramente os entrevistados deveriam mencionar o que compreendiam por "estigma”, em seguida responderam o que "compreendiam por violência". O terceiro questionamento era "se" na visão 
dos entrevistados ambos os conceitos teriam alguma relação. O quarto questionamento foi "se" na visão deles (entrevistados) os profissionais reproduziam o "estigma como expressão da violência" no ambiente de trabalho. Logo, o questionamento posterior foi "se" na visão deles, como profissionais, o estigma seria capaz de agravar o sofrimento mental do paciente psiquiátrico em internação e se o fenômeno poderia ser um agravante para a saúde de tais pacientes. A última questão visou compreender como os profissionais poderiam minimizar a ocorrência do fenômeno nas suas práticas junto aos pacientes.

Do material obtido nas entrevistas foi possível destacar os subtemas mais evidenciados entre os participantes.

\section{RESULTADOS}

Se no senso comum parece fácil definir a estigmatização, os entrevistados foram polissêmicos, utilizando os sinônimos “categorização", “classificação" e "representação" para situá-la, mas as explicações sobre o que é o termo estigma vieram vazias de sentido. Alguns entrevistados mostraram a priori o desconhecimento ou incompreensão do conceito clássico de estigma, o que se evidenciou em algumas falas, que deram conta do estigma como um fenômeno de atribuição de características positivas aos sujeitos "diferentes".

Embora o trabalho tenha contemplado a categoria "saúde mental", a doença mais relacionada ao estigma foi a hanseníase, o que sugeriu em um primeiro momento a dificuldade de enxergarem a estigmatização de seus próprios pacientes.

Sobre a próxima questão, o silêncio antecedeu algumas falas relacionadas ao que seria a violência, e demonstrou o distanciamento necessário da questão para que pudessem refletir a respeito da pergunta. Os profissionais demonstraram a compreensão da violência e a definiram por meio da aproximação com as cenas cotidianas, relacionadas aos problemas de ordem pública e perda de direitos, ou ainda utilizaram para tal a conceituação da OMS.

O diferencial nas falas foi a "violência sutil"; os entrevistados mencionaram que essa violência ocorre junto aos pacientes, porém é quase imperceptível, e deram características dessa tipificação. O uso da violência "sutil" é representado nas falas como o lugar onde os profissionais podem se afirmar como reprodutores da violência sem passarem por julgamentos alheios, ou sem de fato se darem conta de que estão reproduzindo atos naturalizados.

Quando convocados a pensar se o estigma seria uma expressão da violência, a reflexão pareceu ser nova para os profissionais, e um deles relatou que nunca havia pensado a respeito. Quando questionados se os profissionais de saúde mental reproduziam o "estigma como expressão da violência em suas práticas", a pergunta gerou um desconforto, e inicialmente os entrevistados resistiram em respondê-la. Porém, essa pergunta dividiu o grupo. Enquanto alguns afirmaram que na Unidade Psiquiátrica do Hospital Geral em questão os profissionais evitam a todo custo atitudes no sentido de estigmatização ou violência contra os pacientes, um entrevistado afirmou que outros profissionais do hospital, externos à psiquiatria, têm preconceitos sobre o setor. Segundo ele, "quando os profissionais dos outros setores vão até lá, geralmente carregam estereótipos do que podem encontrar, estereótipos estes relacionados à imagem dos pacientes". A psiquiatria foi mencionada como o setor que é evitado, entretanto, é aquele que os demais setores acionam quando foram esgotadas as possibilidades de diálogo com os pacientes. $\mathrm{O}$ diferencial nessa questão foi um dos profissionais se assumir dentro do contexto de estigmatização e violência, dizendo que é humano e se reconhece nesse processo, já que o estigma se dá nas relações humanas, como uma construção social. Para além da sua afirmação, ele colocou a importância de se reconhecer dentro desse meio (social) e ficar atento às ações, que resultam de um pré-conceito.

Os demais profissionais confirmaram que tanto o estigma como a violência estão presentes em suas práticas e se enxergaram nesse contexto, porém, diferente do profissional citado, utilizaram de artifícios para encobri-los nas falas, tais como a mudança do pronome, em que o "eu" foi claramente substituído pelo "você", com a finalidade de garantir certo distanciamento ao citarem os exemplos que lhes eram conhecidos.

Os profissionais concordaram de forma unânime que "o estigma como expressão da violência” é capaz de agir sobre a saúde dos indivíduos, podendo gerar complicações orgânicas, como alergias e náuseas, porém, nem todos os sujeitos terão tais complicações, diferente do aumento do sofrimento mental, que é uma regra para todos. Enquanto o sofrimento do estigma e as manifestações da violência no estigma são comuns a todas as pessoas com transtornos mentais, suas repercussões são individuais e dependem de como esses indivíduos se organizam subjetivamente diante disso. Os participantes afirmaram que cada sujeito vivenciará o sofrimento de modo diferente, o que pode incluir tanto a aceitação como também a opção pelo isolamento total.

\section{DISCUSSÃO}

O estigma é um fenômeno importante que sempre ganhou repercussão na saúde mental. Entretanto, o conhecimento por parte dos profissionais sobre a conceituação ou terminologia se mostrou incipiente.

Nas falas, alguns respondentes exemplificaram o estigma sob o viés da hanseníase e da aids. Os transtornos mentais não foram mencionados.

É essencial considerar que os próprios autores clássicos que trabalharam as relações entre estigma e doenças ao longo da história mencionaram a hanseníase em alguns textos.

Goffman introduziu seus trabalhos explicando que os "loucos" ganharam o status de doentes mentais no século XVIII, porém, antes disso eram segregados junto aos portadores de lepra e tuberculose ${ }^{8}$. 
Foucault descreveu os espaços de exclusão onde os "loucos" permaneciam junto aos portadores de doenças venéreas e libertinos ${ }^{12}$

Anos mais tarde, uma pesquisa publicada comprovou a relação da existência de transtornos mentais em pessoas com lepra, uma vez que o ambiente inóspito onde os indivíduos com transtornos mentais viviam (no referido período) era um desencadeador de doenças como a lepra ${ }^{13}$.

Levando em consideração que os profissionais que pontuaram a hanseníase ou a aids se formaram antes de a Lei 10.216 ser instituída no Brasil, ficou evidente por parte de alguns um conhecimento defasado, envolvendo uma dificuldade de visualizar o estigma no contexto das pessoas com transtornos mentais. Estes apresentaram ao longo do questionário imagens da psiquiatria antiga, restrita ao modelo biomédico. Reiterou-se a necessidade de reciclagem ou capacitação desses profissionais.

Sobre a questão seguinte, envolvendo a conceituação de violência, o termo "violência sutil" utilizado pelos entrevistados, e as explicações tais como foram dadas a respeito dessa tipificação, fazem jus ao fenômeno descrito por Bourdieu, definindo uma tipificação de violência que ocorre de modo suave e invisível e se exerce por vias simbólicas da comunicação ou conhecimento ${ }^{14}$.

As falas principalmente sobre a descrição da violência no espaço de trabalho foram construtivas, uma vez que demonstraram mudanças na tipificação da violência praticada contra as pessoas com transtornos mentais em internação.

Um dos profissionais, ao se posicionar como sujeito, proveniente também da construção social, se reconheceu como reprodutor do estigma e violência junto a seus pacientes. Este foi o único entrevistado que assumiu tal posição. O profissional levantou questões bem próximas a uma das características da violência citada por Arendt.

A autora diz que a violência precisa de uma justificativa e defende que o homem tem tanto a racionalidade quanto a irracionalidade, mas a violência não é algo natural. Mesmo que o homem em determinado momento haja dentro da irracionalidade, o uso da violência é um instrumento construído nas relações sociais. A violência seria um fim último para a tentativa de manter o poder nas relações ${ }^{15}$.

$\mathrm{O}$ entrevistado destacou que essa violência sutil (que ele próprio comete) não é imperceptível somente aos pacientes, mas também àqueles que a cometem. Ele comentou que não há a possibilidade de medir e pensar em cada gesto ou ação que serão dirigidos aos pacientes, embora em determinado momento ocorra a possibilidade de pensar sob a ótica racional, de forma consciente, e entender o fim para o qual foi utilizada.

De modo geral, mais um aspecto relevante foi considerado: a preocupação que os profissionais manifestaram em se atentarem para que violência ou estigma não sejam corriqueiros no seu cotidiano.

Nas últimas perguntas, as falas mostraram que os entrevistados, ao mesmo tempo em que se assumem (indiretamente) cometendo os fenômenos negativos, também se sentem responsáveis pela desconstrução do estigma e da violência.

Se no início das entrevistas os profissionais responderam com o silêncio, demonstraram estranheza ou descrédito nas questões, ou ainda resistiram diante das respostas, houve uma quebra nesse contexto à medida que a entrevista foi ocorrendo. Ao longo das entrevistas, a própria definição do estigma se aproximou mais do cotidiano no qual trabalham e a visão se direcionou para seus pacientes, considerando-os como sujeitos que possuem uma história.

A fala do estigma permitiu aos profissionais repensarem a Reforma Psiquiátrica como um processo contínuo, que ocorre até hoje, no qual eles (profissionais de saúde mental) são os principais agentes de mudança. Nesse sentido, os profissionais têm conhecimento dos seus papéis, objetivando a garantia de princípios que estão além da atenção básica: estabelecer uma atenção para além da atenção primária, em outros níveis, com profissionais capacitados principalmente para o cuidado aos grupos vulneráveis, utilizando técnicas preventivas (nesse caso seriam na prevenção do estigma e violência), respeitando os sujeitos ou grupos em suas histórias e vivências singulares, é o que legitima a integralidade, como um dos princípios do SUS ${ }^{16}$.

Nas falas finais, um psiquiatra viu no diagnóstico a reprodução e legitimação do estigma.

O diagnóstico em si já rotula e estereotipa o paciente. As rotulações e estigmatizações geram sofrimento, já que as pessoas com transtornos mentais passam a ser reduzidas a suas doenças e acabam por aceitarem-se como loucos e doentes, conforme essas titulações lhes são atribuídas ${ }^{17}$.

Houve consenso por parte dos entrevistados sobre o sofrimento desencadeado pela estigmatização. Porém, o sofrimento foi colocado como individual, e o modo como cada paciente responderá a ele dependerá de alguns fatores.

Os fatores reconhecidos como de risco para a violência contra pessoas com transtornos mentais seriam: a falta de conhecimento sobre seus direitos, a desinformação sobre o tratamento, o isolamento das famílias, a dificuldade de comunicação, as poucas oportunidades de trabalho e a perda da autonomia ou dependência de familiares para as rotinas do dia a dia. Por outro lado, os fatores de proteção incluem: a manutenção do tratamento adequado, $\mathrm{o}$ apoio às famílias e a inserção em atividades socioculturais ${ }^{18}$.

Os profissionais estão enquadrados nessa zona de apoio, portanto, necessitam estar aptos para atuar com os fatores de proteção. É por meio da educação que se pode trabalhar e articular esses fatores; A reformulação desse processo educacional vai desde a reorganização dos currículos para os profissionais de saúde, aproximando-os e capacitando-os para trabalharem no contexto social desse paciente, até a oferta de educação voltada também para a sociedade civil, alterando as imagens equivocadas que carregam, orientando-os inclusive no sentido do diagnóstico e da medicalização. 
Por mais que alguns profissionais, principalmente os da área médica, possuam cursos de pós-graduação, é necessário que as estratégias voltadas para a formação sejam constantes e envolvam a realidade social, o que se justifica pela Educação Permanente, sugerida como essencial a essa Unidade Psiquiátrica de Hospital Geral, uma vez que reforçaria a importância do trabalho em equipe, da inclusão/aproximação entre as diferentes categoriais e maior compreensão sobre os assuntos aqui tratados, valorizando a integralidade do sujeito internado.

Ao abrir um espaço para que os participantes fizessem observações, um deles citou o desejo de modificar a Unidade Psiquiátrica, inserindo um terapeuta ocupacional na equipe e propondo um trabalho integrado entre as diversas categorias, no qual os pacientes internados fossem estimulados ao desenvolvimento da criatividade. Nessa fala observamos que um dos problemas apresentados na Unidade Psiquiátrica era a falta de comunicação e a diferenciação entre as categorias profissionais. Os enfermeiros não participam das reuniões com os psiquiatras e psicólogos. Cogitou-se a hipótese de a raiz desse problema se iniciar na admissão das categorias para o serviço: os enfermeiros são profissionais do Hospital Geral e, em algum momento, foram alocados no setor de psiquiatria, enquanto os psiquiatras e psicólogos foram designados para aquele setor específico. Tal divisão deu a impressão da existência de uma equipe à parte, que se organizou dentro da equipe principal. A questão não foi debatida mais a fundo, porém, foi importante inseri-la nessa análise, uma vez que pode demonstrar muito sobre a divisão, que repercute nas falhas de comunicação.

Por fim, evidenciou-se que ao menos nesse campo de investigação ocorreram avanços após a Reforma Psiquiátrica, em termos de novas possibilidades para os pacientes.

Promulgada a Lei Federal no 10.216/01, e aprovadas as demais leis estaduais da Reforma Psiquiátrica, legitima-se outro modelo estrutural, embora a transformação da mentalidade social seja mais complexa ${ }^{19}$.

Avalia-se a necessidade de repensar algumas práticas que ainda ocorrem nos dispositivos, visando à reorientação e formação não só dos profissionais, mas da sociedade civil, para que não se fale em "acabar com o estigma”, mas tomar consciência do fenômeno, reduzindo a intolerância frente aos diferentes devires.
É reconhecido que as ciências da saúde passaram por diversas mudanças ao focar as pessoas e realidades sociais para além das doenças. Ao reconhecer que antes do doente há um sujeito, rompe-se com o modelo teórico-conceitual. A reforma do modelo tradicional inicia-se na Europa e contribui para a reforma brasileira ${ }^{20}$.

Contrariando o pressuposto inicial da pesquisa, em que se acreditou que na visão dos entrevistados violência e estigma estariam dissociados, os entrevistados reconheceram que o estigma e a violência estão interligados, afirmando que a violência nem sempre implica o estigma, mas o estigma sempre comportará a violência. Outro ponto de negação do pressuposto se deu pelas falas dos profissionais, os quais, mesmo resistentes, por meio do conceito "violência sutil" demonstraram conhecimentos sobre a "violência simbólica" e a associaram com determinadas práticas que reproduzem estigma e violência no ambiente de trabalho.

A Reforma Psiquiátrica proporcionou a criação de um novo modelo de assistência. $\mathrm{Na}$ Unidade, a visão estrutural rompeu com os leitos-chão, com os ambientes frios e inóspitos, fato que se agregou à nova lógica do cuidado. A precariedade que se evidenciava na lógica da violência física e da negligência foi aos poucos excluída do imaginário social.

Embora o período pós-Reforma Psiquiátrica reverbere novas organizações, não é possível afirmar que a violência saiu de cena. Tal fato pôde ser confirmado na visão dos próprios entrevistados. E, por mais que a violência existente seja "sutil", ela age por vias psíquicas.

A saída diante de tal violência seria, a priori, o conhecimento dos fenômenos e dos processos que os determinam.

A noção da integralidade do cuidado chegou a um espaço onde nem sequer se permitia pensá-la. O Ministério da Saúde inclui na sua agenda a violência como um fenômeno relevante. Portanto, para que haja o gozo pleno da saúde, faz-se necessário combater a violência. Essa pesquisa servirá como orientação para os demais interessados na análise atual da percepção do estigma e violência, principalmente nos serviços de saúde mental. A monitoração do fenômeno em tais dispositivos se faz necessária e abre possibilidades para novas investigações.

\section{REFERÊNCIAS}

1. Minayo MCS. Conceitos, teorias e tipologias de violências: a violência faz mal à saúde individual e coletiva. In: Njaine K, Assis SG, Constantino $\mathrm{P}$, organizadores. Impactos da violência sobre a saúde. Rio de Janeiro: Editora Fiocruz; 2009. p. 21-42.

2. Krug EG, Mercy JA, Dahlberg LL, Zwi AB. The world report on violence and health. Lancet. 2002;360(9339):1083-8. http://dx.doi.org/10.1016/ S0140-6736(02)11133-0. PMid:12384003.
3. Brasil. Portaria MS/GM nº 737, de 16 de maio de 2001. Política Nacional de Redução da Morbimortalidade por Acidentes e Violências. Diário Oficial da União, Brasília, 18 de maio de 1996.

4. Brasil. Reforma psiquiátrica e política de saúde mental no Brasil: conferência regional de reforma dos serviços de saúde mental - 15 anos depois de Caracas [Internet]. Brasília: Ministério da Saúde; 2005 [citado em 2016 Jul 10]. Disponível em: http://bvsms.saude.gov.br/bvs/publicacoes/ Relatorio15_aCnos_Caracas.pdf 
5. Brasil. Saúde mental no SUS: acesso ao tratamento e mudança do modelo de atenção [Internet]. Brasília: Ministério da Saúde; 2007 [citado em 2016 Jul 10] (Relatório de Gestão; 2003-2006). Disponível em: http://bvsms. saude.gov.br/bvs/publicacoes/07_0416_M.pdf

6. Delgado PGG. Perspectivas da psiquiatria pós-asilar no Brasil. In: Tundis SA, Costa NR, coordenadores. Cidadania e loucura: políticas de saúde mental no Brasil. Petrópolis: Vozes; 1987.

7. Brasil. Portaria GM/MS n ${ }^{4} 483 / 2014$. Redefine a Rede de Atenção à Saúde das Pessoas com Doenças Crônicas no âmbito do Sistema Único de Saúde (SUS) e estabelece diretrizes para a organização das suas linhas de cuidado. Diário Oficial da União, Brasília, 02 de abril de 2014.

8. Goffman E. Estigma: notas sobre a manipulação da identidade deteriorada. 4. ed. Rio de Janeiro: LTC; 1988.

9. Becker H. Outsiders: estudos de sociologia do desvio. Rio de Janeiro: Jorge Zahar; 2008. $15 \mathrm{p}$

10. Basaglia F. A instituição negada. Rio de Janeiro: Graal; 1985

11. Braun V, Clarke V. Using thematic analysis in psychology. Qual Res Psychol. 2006;3(2):77-101. http://dx.doi.org/10.1191/1478088706qp063oa.

12. Foucault M. Vigiar e punir: nascimento da prisão. Petrópolis: Vozes; 1987. (Trad. LMP Vassalo).

13. Araujo GS, Pereira SM, Santos DN. Revisão sobre tuberculose e transtornos mentais comuns. Revista Eletrônica Gestão \& Saúde. 2014;5(2):716-26.
14. Bourdieu P. O poder simbólico. 7. ed. Rio de Janeiro: Bertrand Brasil; 2004.

15. Arendt H. Da violência. Brasília: Ed. Universidade de Brasília; 1985. (Trad. MCD Trindade).

16. Pinheiro R. Integralidade. In: Fundação Oswaldo Cruz - FIOCRUZ. Dicionário da Educação Profissional em Saúde [Internet]. Rio de Janeiro: Escola Politécnica de Saúde Joaquim Venâncio; 2009 [citado em 2015 Dez 04]. Disponível em: http://www.epsjv.fiocruz.br/dicionario/verbetes/intsau. html

17. Silva RS, Brandalise F. O efeito do diagnóstico psiquiátrico sobre a identidade do paciente. Mudanças Psicol Saúde. 2008;16(2):123-9. http:// dx.doi.org/10.15603/2176-1019/mud.v16n2p123-129.

18. Toledo LM. Violência: orientações para profissionais da atenção básica de saúde. Rio de Janeiro: ENSP; FIOCRUZ; 2013.

19. Paula KVS. A questão da saúde mental e atenção psicossocial: considerações acerca do debate em torno de conceitos e direitos. Physis. 2008;18(4):83640. http://dx.doi.org/10.1590/S0103-73312008000400014.

20. Amarante PDC. Saúde mental e atenção psicossocial. Rio de Janeiro: FIOCRUZ; 2007. 